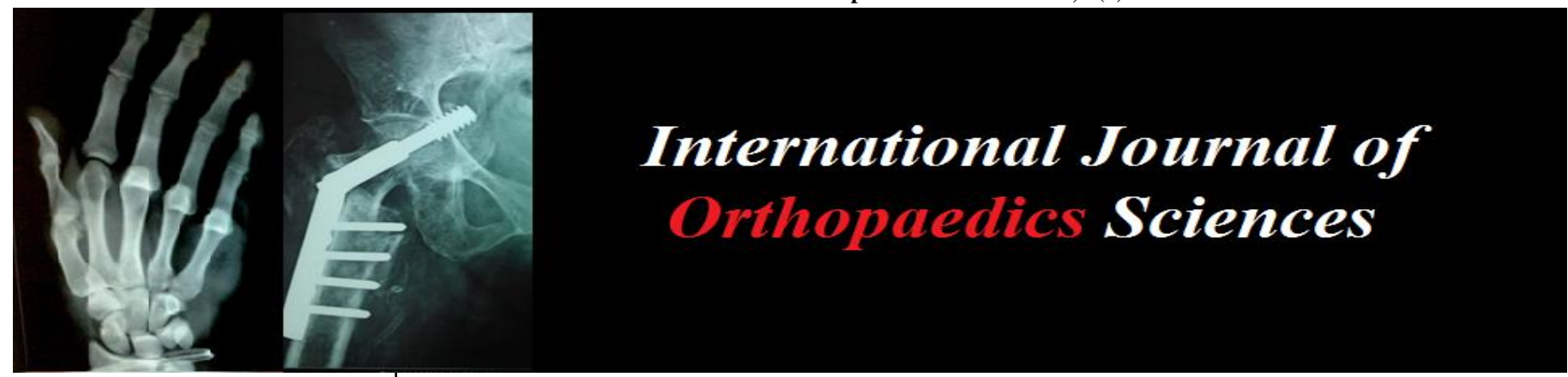

ISSN: $2395-1958$

IJOS 2019; 5(1): 07-11

(C) 2019 IJOS

www.orthopaper.com

Received: 02-11-2018

Accepted: 05-12-2018

Dr. Maulik B Shah

Assistant Professor, Department of Orthopedics, Shardaben

Municipal Hospital \& NHL

Municipal Medical College,

Ahmedabad, Gujarat, India

Dr. Somshekar

Professor and Unit head,

Department of orthopaedics,

Kempegowda Institute of

Medical Sciences, Bangalore,

Karnataka, India

Dr. Nimish Patel

Professor and HOD, Department

of Orthopedics, Shardaben

Municipal Hospital \& NHL

Municipal Medical College,

Ahmedabad, Gujarat, India

Dr. Rajesh Chawda

Associate Professor and Unit

head, Department of

Orthopedics, Shardaben

Municipal Hospital \& NHL

Municipal Medical College,

Ahmedabad, Gujarat, India

Correspondence

Dr. Maulik B Shah

Assistant Professor, Department

of Orthopedics, Shardaben

Municipal Hospital \& NHL

Municipal Medical College,

Ahmedabad, Gujarat, India

\section{Prospective study of the surgical management of distal tibia extra-articular metaphyseal tibial fractures managed with CRIF with IMIL tip locking nails: A study of 20 patients}

\author{
Dr. Maulik B Shah, Dr. Somshekar, Dr. Nimish Patel and Dr. Rajesh \\ Chawda
}

DOI: https://doi.org/10.22271/ortho.2019.v5.11a.02

\begin{abstract}
Background: Distal tibia extra articular metaphyseal tibial fractures are difficult to manage because of the hour glass shape of the distal tibia poses a difficulty to achieve fixation with intramedullary nails. For the past decade, nailing and plating for fracture reduction has been successful in treating fractures of lower extremity especially distal tibia.

Objectives: To prospectively study the functional and radiological outcome of distal tibia fractures managed by CRIF with IM tip locking nails.

Materials and Methods: Patients with fractures of distal tibia extra articular metaphyseal tibial fractures managed with CRIF with IMIL tip locking nails were followed up prospectively till fracture union. Their functional and radiological outcome was assessed by using IOWA knee and ankle scoring index.

Conclusion: All fractures united well. No infections were seen. Distal tibia fractures can be managed well with CRIF with IM tip locking tibial nails. 6 patients developed a coronal plane deformity of $<5$ degrees but all patients had good functional outcome.
\end{abstract}

Keywords: Distal tibial fracture, IMIL nail, Tip locking nail, IOWA knee and ankle evaluation

\section{Introduction}

The distal tibia was defined as the area within two Müller squares of the ankle joint, in which the proximal and the distal segments of long bones are defined by a square whose sides have the same length as the widest part of the epiphysis ${ }^{[1]}$.

The difficulty in treating the fractures of distal tibial end is exemplified by orthopedists, who in the first half of twentieth century believed these injuries were so severe and fraught with so many complications that the fracture was deemed not amenable for surgical reconstruction ${ }^{[2]}$.

Distal tibial fractures represent a significant challenge to most of the surgeons today. They are only $1-10 \%$ of lower extremity fractures ${ }^{[3]}$. Conservative treatment by cast application leads to prolonged immobilization, leading to ankle and knee stiffness affecting quality of life of the patient ${ }^{[4]}$. Maintaining reduction in a cast is difficult and requires frequent office visits, radiographs, and adjustments ${ }^{[5]}$. Fractures of the distal tibia can be challenging to treat because of the limited soft tissue, the subcutaneous location, and poor vascularity.

Although intramedullary nailing is accepted as a method for stabilizing diaphyseal tibial fractures, its role in the treatment of distal metaphyseal fractures has not been well defined ${ }^{[6-9]}$. Fixation with intramedullary devices is a technique that is already familiar to most surgeons. It spares the extra osseous blood supply, allows load-sharing, and avoids extensive soft-tissue dissection. Recent changes in intramedullary nail design have extended the spectrum of fractures amenable to this type of fixation. Concerns regarding difficulties with reduction, distal propagation of the fracture, hardware failure, and inadequate distal fixation leading to mal-alignment have slowed the acceptance of intramedullary nailing as a treatment for distal metaphyseal fractures ${ }^{[5]}$.

The purpose of this study was to evaluate reamed intramedullary nailing of distal metaphyseal tibial fractures located within 2 Muller squares of the ankle joint ${ }^{[5]}$. 


\section{Material and Methods}

During a study duration of 18 months 20 skeletally mature adults with a post traumatic tibial fracture were treated with intramedullary nailing. Biplanar radiographs were obtained to confirm the diagnosis. Patients whose fractures extended within two mullers squares of the ankle mortise were included into the study after obtaining written informed consent for surgery and also for inclusion into the study. Patients with substantial intra articular extension were excluded from the study group. 5 patients had open fractures in which primary closure could be achieved and all 5 of them had been operated within 8 hours of injury under after through wound debridement. As per AO classification fractures that were 43A1, 43A2, 43A3 were included in the study. Pathological fractures, fractures in immature skeletons, old neglected fractures and old fractures with implant failure weren't included in this study.

\section{Preoperative evaluation}

All patients underwent routine pre op evaluation and other major injuries were ruled out and pre-operative fitness was obtained. Patients were adequately counselled.

\section{Post-operative care}

Immediate post-operative complications like fat embolism, compartment syndrome, neurological damage and vascular injury is looked for. Intravenous antibiotic regimen was continued for 5-7 days after the surgery. Another 5 days of oral antibiotics were advised. Suture or staple removal was done at 10-12th post-operative day. Non-weight bearing of the patient using standard walking frame was done from the first postoperative day under the supervision. Active quadriceps exercises are restarted on the $1^{\text {st }}$ post-operative day with active ankle and toe movements with knee mobilization as far as the patient is comfortable and free of pain. The patient is made to ambulate from the 3rd post-operative day without bearing weight on the operated leg with crutches or walker.

Post-operative radiographs were obtained for assessment of fixation. Also radiographs were obtained at subsequent follow up visits to assess for secondary loss of reduction/ development of deformity and fracture union. The follow up lasted 6-10 months. The assessment was done as per fracture union grading in the Iowa knee and ankle evaluation system ${ }^{[10]}$. At follow ups the patients were also assessed for the functional outcome based on the Iowa knee and ankle evaluation rating system. Partial and full weight-bearing were allowed based on radiological and consolidation of the fractures. The fracture was designated as united, when there was periosteal bridging callus at the fracture site at least in three cortices in the anteroposterior and lateral views. Trabeculations extending across the fracture site was also taken into consideration ${ }^{[10]}$.

\section{Results}

The results of our study are tabulated as below.

Age distribution

\begin{tabular}{|c|c|c|}
\hline Age group & number & \% \\
\hline $18-20$ & 1 & 5 \\
\hline $21-30$ & 4 & 20 \\
\hline $31-40$ & 7 & 35 \\
\hline $41-50$ & 2 & 10 \\
\hline $51-60$ & 4 & 20 \\
\hline $61-70$ & 2 & 10 \\
\hline Total & 20 & $100 \%$ \\
\hline
\end{tabular}

Mean Age 41.05 years
Sex distribution

\begin{tabular}{|c|c|c|}
\hline Sex & Number & \%age \\
\hline Male & 15 & 75 \\
\hline Female & 5 & 25 \\
\hline Total & 20 & 100 \\
\hline
\end{tabular}

\section{Occupation}

Most of our patients were of low to middle class families mostly businessmen having sedentary lifestyles.

\begin{tabular}{|c|c|c|}
\hline Occupation & Number & \%age \\
\hline Farmer & 3 & 15 \\
\hline Housewife & 5 & 25 \\
\hline Businessman & 7 & 35 \\
\hline Labourer & 1 & 5 \\
\hline Student & 3 & 15 \\
\hline Teacher & 1 & 5 \\
\hline Total & 20 & 100 \\
\hline
\end{tabular}

Type of Fracture

\begin{tabular}{|c|c|c|}
\hline Type & Number & \% age \\
\hline Open & 5 & 25 \\
\hline Closed & 15 & 75 \\
\hline Total & 20 & 100 \\
\hline
\end{tabular}

Mode of Injury

\begin{tabular}{|c|c|c|}
\hline Mode & Number & \% age \\
\hline Road Traffic Accident & 16 & 80 \\
\hline Self - Fall & 4 & 20 \\
\hline Total & 20 & 100 \\
\hline
\end{tabular}

Side Predilection

\begin{tabular}{|c|c|c|}
\hline Side & Number & \% age \\
\hline Right & 14 & 70 \\
\hline Left & 6 & 30 \\
\hline Total & 20 & 100 \\
\hline
\end{tabular}

Average Duration of surgery was 83 minutes. Average number of days of hospital stay is 11 days. No post op infections. No patients needed implant removal due to infection or other causes.

Functional outcome: It was assessed using the IOWA knee and ankle evaluation rating system ${ }^{[10]}$ and is tabulated as below

\begin{tabular}{|c|c|c|c|}
\hline $\begin{array}{c}\text { Average Score as per IOWA knee } \\
\text { evaluation rating system }\end{array}$ & $\begin{array}{c}\mathbf{6} \\
\text { weeks }\end{array}$ & $\begin{array}{c}\mathbf{1 2} \\
\text { weeks }\end{array}$ & $\begin{array}{c}\mathbf{2 4} \\
\text { weeks }\end{array}$ \\
\hline Knee Activity Scoring (max 35) & 9 & 14 & 21 \\
\hline Knee freedom From pain scoring (max 35) & 27 & 35 & 35 \\
\hline Knee Gait scoring (max10) & 8 & 8 & 9 \\
\hline Knee ROM score $(\max 10)$ & 10 & 10 & 10 \\
\hline
\end{tabular}

\begin{tabular}{|c|c|c|c|}
\hline $\begin{array}{c}\text { Average Score as per IOWA ankle } \\
\text { evaluation rating system }\end{array}$ & 6 weeks & $\begin{array}{c}\mathbf{1 2} \\
\text { weeks }\end{array}$ & 24 weeks \\
\hline Ankle activity scoring (max 40) & 0 & 0 & 25 \\
\hline Ankle freedom from pain scoring(max 40) & 18 & 29 & 37 \\
\hline Ankle gait scoring (max10) & 2 & 8 & 10 \\
\hline
\end{tabular}

Average Grade of callus formation

\begin{tabular}{|c|c|c|c|}
\hline Grade of callus formation N = 20 & 6 weeks & $\mathbf{1 2}$ weeks 24 weeks \\
\hline 1 & $0(0 \%)$ & $0(0 \%)$ & $0(0 \%)$ \\
\hline 2 & $0(0 \%)$ & $0(0 \%)$ & $9(45 \%)$ \\
\hline 3 & $0(0 \%)$ & $18(90 \%)$ & $11(55 \%)$ \\
\hline 4 & $4(20 \%)$ & $2(10 \%)$ & $0(0 \%)$ \\
\hline 5 & $16(80 \%)$ & $0(0 \%)$ & $0(0 \%)$ \\
\hline
\end{tabular}


Assessment of Coronal deformity

\begin{tabular}{|l|l|l|l|}
\hline Coronal Angulation & 6 weeks & 12 weeks & 24 weeks \\
\hline Varus $\left(>5^{\circ}\right)$ & $3(15 \%)$ & $3(15 \%)$ & $3(15 \%)$ \\
\hline Valgus $\left(>5^{\circ}\right)$ & $3(15 \%)$ & $3(15 \%)$ & $3(15 \%)$ \\
\hline No deformity & $14(70 \%)$ & $14(70 \%)$ & $14(70 \%)$ \\
\hline Total & $20(100 \%)$ & $20(100 \%)$ & $20(100 \%)$ \\
\hline
\end{tabular}

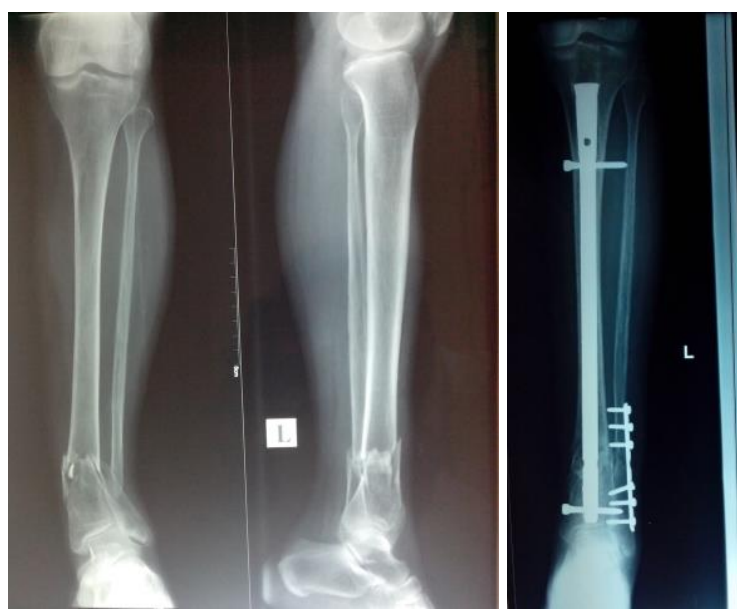

Pre op

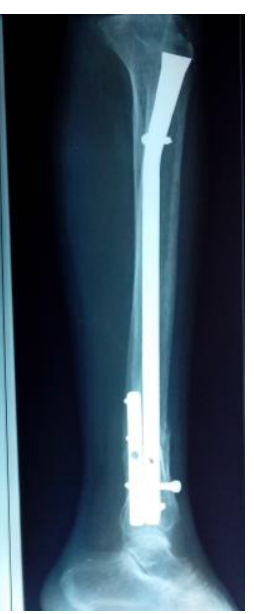

At union

Case 1

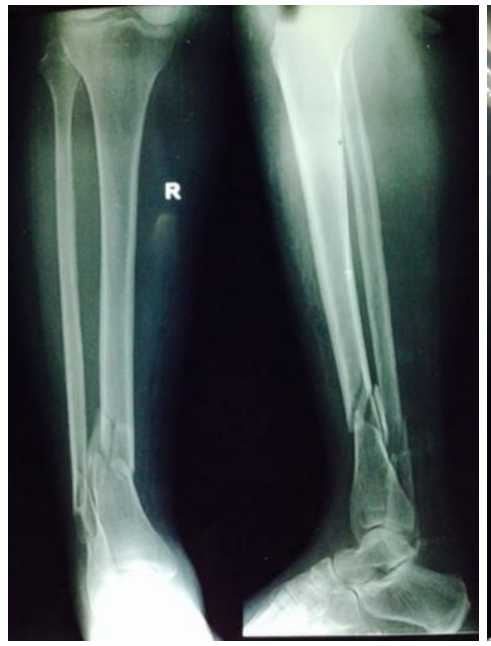

Pre op

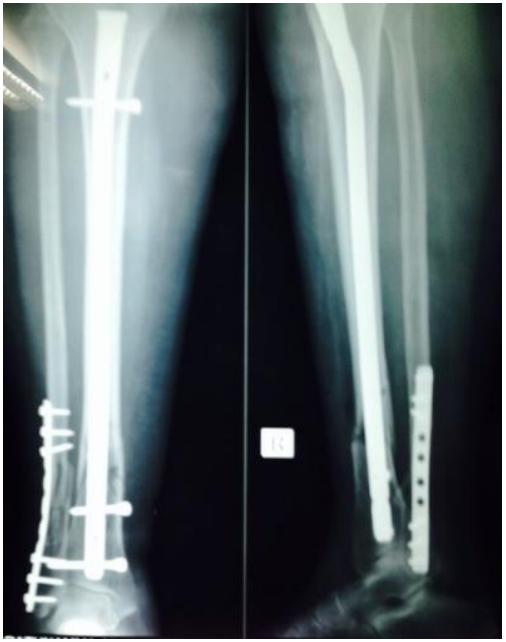

At union

Case 2

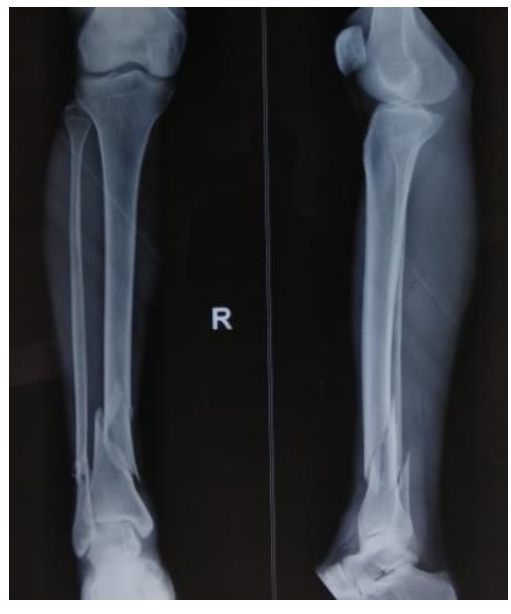

Pre op

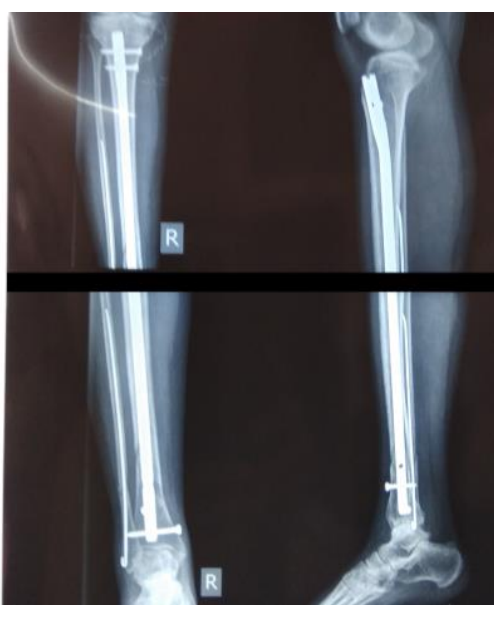

At Union

Case 3 
Fractures of distal tibia are among the most difficult fractures to treat effectively. The status of the soft tissue, degree of comminution sustained at the time of injury affects the long term clinical results. The goal of the operative treatment is to obtain anatomical alignment of the joint surface by providing enough stability to allow early movement this should be accomplished using techniques that minimize osseous and soft tissue devascularization in the hopes of decreasing the complications resulting from treatment ${ }^{[11]}$.

The present study was undertaken to study the functional and radiological outcome of intramedullary nailing for distal tibia fractures.

\section{Age distribution}

In this study it was found that the average age of patients with such injuries was 41 years. $(19-65)$. Here is a comparison by other authors

\begin{tabular}{|c|c|c|c|}
\hline Study & $\begin{array}{c}\text { Minimum age } \\
\text { (years) }\end{array}$ & $\begin{array}{c}\text { Maximum } \\
\text { age (years) }\end{array}$ & Average \\
\hline TT Guo et al. ${ }^{[12]}$ & 23 & 70 & 42 \\
\hline C Mauffry et al. ${ }^{[1]}$ & 23 & 70 & 46 \\
\hline Somshekar et al. ${ }^{[11]}$ & 19 & 68 & 46 \\
\hline This study & 19 & 65 & 41 \\
\hline
\end{tabular}

\section{Sex distribution}

In our study there is a male pre ponderance

\begin{tabular}{|c|c|c|}
\hline Study & Male & Female \\
\hline TT Guo et al. ${ }^{[12]}$ & 50 & 35 \\
\hline C Mauffry et al. ${ }^{[1]}$ & 66 & 34 \\
\hline${\text { Somshekar } \text { et al. }{ }^{[11]}}^{\text {This study }}$ & 80 & 20 \\
\hline
\end{tabular}

Most common mode of injury was road traffic accident and average duration of surgery was 83 minutes. Most of the cases were performed on a traction table. Knee pain is a common complaint post op which is due to the operative trauma which improves over time with healing and analgesics. If a nail of incorrect length (longer) is used for fixation, it can cause residual pain in the knee joint due to impingement of the patella tendon. None of our patients needed implant removal due to impingement or infection. In our study we started ROM movements at the ankle and knee as soon as the patient was comfortable under adequate analgesia. Patients were kept on non-weight bearing mobilization for 4-6 weeks post op and partial weight bearing was initiated after 4-6 weeks. As radiological union progressed patient was allowed full weight bearing at around 10-12 weeks. At around 24-26 weeks radiological union was achieved.

Radiological union

\begin{tabular}{|c|c|}
\hline Study & Mean time to union (in weeks) \\
\hline Kasper W et al. ${ }^{[13]}$ & 19 \\
\hline Ajay Krishnan et al. ${ }^{[14]}$ & 20 \\
\hline TT Guo et al. ${ }^{[12]}$ & 17.6 \\
\hline Somshekar et al. ${ }^{[11]}$ & 26 \\
\hline Present study & 24 \\
\hline
\end{tabular}

\section{Complications}

In a study conducted by C. Mauffrey et al. ${ }^{[1]}$ three patients (6.8\%) with IM nail had wound problems and one patient developed compartment syndrome. In a study by Kasper et al. [13] 2 patients $(16.7 \%)$ of IM nailing group had varus/valgus malalignment of $>5^{\circ}$, two $(16.7 \%)$ patients had rotational malalignment of $>15^{\circ}$ after ORIF versus $3(25 \%)$ after IM nailing. In a study by Somshekar et al. ${ }^{[11]} 40 \%$ patients who underwent IM nailing had a varus/valgus deformity of less than 5 degrees. In this study we had comparable results with $30 \%$ (6 patients) having a varus/ valgus deformity. None of our patients needed implant removal due to an infection or impingement.

\section{Pitfalls of our study}

Small sample size of 20 many not be representative of the entire cohort of patients with such fractures. A larger sample size and a longer follow up will be more conclusive. Also the cases were performed by more than one surgeon, hence difference in operative techniques and acceptance of fracture reduction may also ha a role to play in the outcome.

\section{Conclusion}

In this study functional outcome of 20 patients with extra articular tibia fractures were studies prospectively. Average age was 41 years with a male preponderance. Most of the injuries were due to a road traffic accident. Average operating time was 83 minutes and most of our cases were performed on a traction table. No Poller screws were used. Fibula was fixed if the fracture was within $5 \mathrm{~cm}$ of ankle mortise to gain height and correct rotation using either plate or intramedullary nail depending on skin condition and surgeon preference.

\section{References}

1. Mauffrey C, McGuinness Parsons N. A randomized pilot trial of locking plate fixation versus intramedullary nailing for extra-articular fractures of the distal tibia $\mathbf{J}$ Bone Joint Surg Br. 2012; 94-B:704-8.

2. Martin JS, Marsh JL, Bonar SK, De Coster TA, Found EM. Assessment of the AO/ASIF fracture classification for the distal tibia, J Orthop Trauma. 1997; 11:477-483.

3. Michael Sirkin, Roy Sanders. The treatment of pilon fractures, Clinic Orthop. 2001; 32(1):91-102.

4. John Charnley. The closed treatment of common fractures. Cambridge Colt books Ltd, 1999.

5. Sean Nork E et al. Intramedullary Nailing of Distal Metaphyseal Tibial Fractures, The Journal of bone and Joint Surgery. 2005; 87-A(6):1213-1221.

6. Konrath G, Moed BR, Watson JT, Kaneshiro S, Karges DE, Cramer KE. Intramedullary nailing of unstable diaphyseal fractures of the tibia with distal intraarticular involvement. J Orthop Trauma. 1997; 11:200-5.

7. Mosheiff R, Safran O, Segal D, Liebergall M. The unreamed tibial nail in the treatment of distal metaphyseal fractures. Injury. 1999; 30:83-90.

8. Robinson CM, McLauchlan GJ, McLean IP, CourtBrown CM. Distal metaphyseal fractures of the tibia with minimal involvement of the ankle. Classification and treatment by locked intramedullary nailing, J Bone Joint Surg Br. 1995; 77:781-7.

9. Tyllianakis M, Megas P, Giannikas D, Lambiris E. Interlocking intramedullary nailing in distal tibial fractures Orthopedics 2000; 23:805-8.

10. Thomas Merchant C, Frederick Dietz R, Long term follow up after fracture of the tibial and fibular shafts; The Journal of Bone and Joint Surgery. 1989; 711(4):500-606.

11. Somshekar et al. A comparative study of functional outcome of distal tibial extra-articular fracture fixed with intramedullary interlocking nail versus locking compression plate, International Journal of Orthopaedics 
Sciences. 2017; 3(2):80-85.

12. Guo JJ, Tang N, Yang HL, Tang TS. A prospective, randomized trial comparing closed intramedullary nailing with percutaneous plating in the treatment of distal metaphyseal fractures of the tibia Bone Joint Surg [Br]. 2010; 92-B:984-8.

13. Kasper Janssen W, Jan Biert, Albert van Kampen. Revised: 5 July 2006 / Accepted: 7 July 2006 / Published online: 12 December 2006\# Springer-Verlag, 2006.

14. Ajay Krishnan, Chetan Peshin, Dara Singh. Intramedullary nailing and plate osteosynthesis for fractures of the distal metaphyseal tibia and fibula Journal of Orthopaedic Surgery. 2009; 17(3):317-20. 